الخصائص السيكومترية لمقياس سلوك إيذائ الذات للدى الأطفال الذاتوبين

مستخلص بحث من رسالة ماجستير فى التربية تخصص (صحة نفسية)

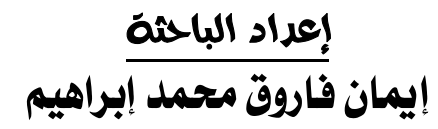

للحصول على درجة الماجستير في التربية

(تخصص: صحة نفسية)

\title{
إض إن
}

دامتمد محمود عبد النبي أستاذ علم النفس التزبوي التتفرغ كلية التربيةـ جامعة الفيوم
أ.د/ فيوليت فؤاد إبراهييم

أستاذ الصحة النفسية والإرشاد النفسي فئي

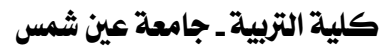

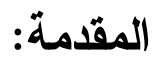

يُعد اضطر اب الذاتوية أكثر الإعاقات التطوريــة صـــوبة بالنــسبة للطفـلـ وتعرض هذا الاضطر اب إلى صعوبات متعددة وقصور و اضتح سو اء فــى أســـاليب

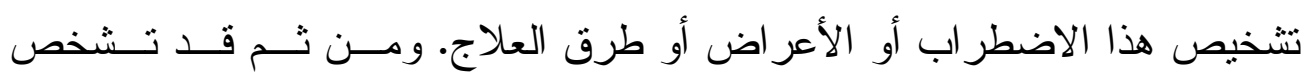
الأطفال الذاتويين من خلال قو ائم التشخيص لهذا الاضطر اب علــى أنهـــم معــاقون عقليا حيث تعتمد تحديد مثل هذه المشكلات على ملاحظة المظاهر الـسلوكية ممــــا ترتب عليه الخلط بين اضطر اب و آخر يختلف عنه تماما.

ويعد هذا الاضطر اب من الاضطر ابات النمائية المنتشرة أي التي تؤثز علـى

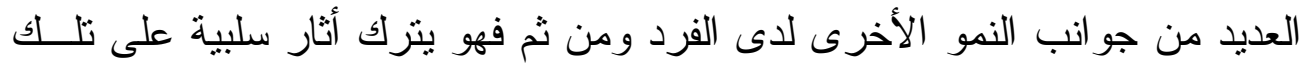
الجو انب ومن بينها النمو المعرفي و الاجتماعي و الانفعالي للطفل وعلى سلوكه بوجه عام أيضا وهو الأمر الذي يؤدى إلى حدوث أثنار سلبية على العملية النمائية بأسر ها. (عادل عبد الله: r ...r، (1) )

ويعد و اضطر اب الذاتويه أحد الاضطر ابات الحديثة التي تصيب العديــــــن مـن الأطفال ويتضح ذلك في صعوبة تحديد الأساليب الحقيقية لهذا الاضطر اب النمـائى 
الثامل الذي يتضح في المشكلات السلوكية والقصور الاجتماعي و المعرفي النــاتج عنه للحد من آثاره، ليس هذا فحسب، بل إن المشكلة الجسيمة التي تو اجه العـاملين

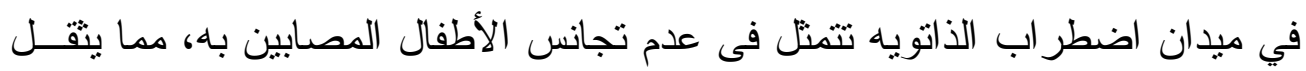
كو اهلهم في سبيل تحديد الخدمات المقدمة لهم، بما يتتاسب وخصائص ومشكلات كل طفل على حده.

كما يرى البعض انه بمثابة إعاقة عقلية و اجتماعية منز امنة (تحدث فــي ذات الوقت) تتصف بالعزلة و الانطو اء، وقصور في السلوكيات المقبولة اجتماعيا، فـضلاً عن ذللك يصاحبه ظهور العديد من الاضطر ابات السلوكية منل (سلوك إيذاء الــذات.

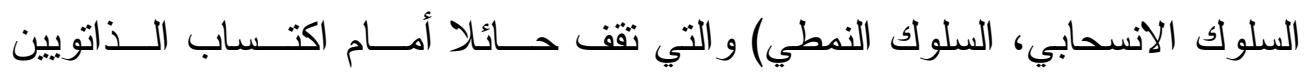

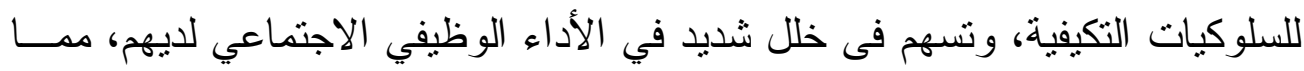
يجعلهم غير قادرين على التو اصل اللفظي أو التفاعل الاجتماعي مع الآخرين الأمــر الذي يشكل عقبة في دمجهم في التعليم مع أقر انهم أو حتى اندماجهم فــي المجتمــع.

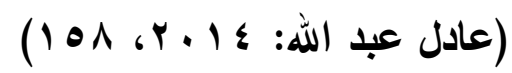

ويعد إيذاء الذات من أكثر الاضطر ابات خطورة و إز عاجاً، لتعدد أثنكاله ويقدر أن ما يزيد عن نسبة (0\%) من الأطفال الذاتويين يقومون به بدرجة مرتفعة لفتـرة

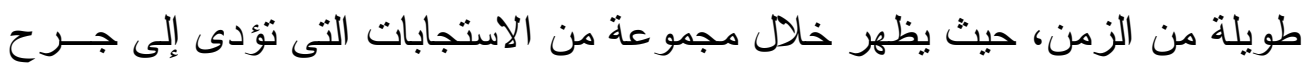

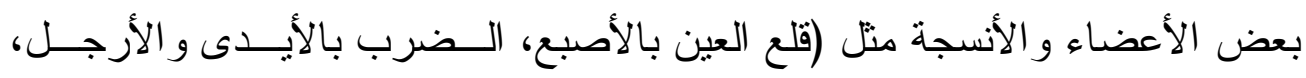
عض أعضاء الجسد). (Edelson \&Johnson, 2016: 14). مشكلة الار اسة:

يعانى الأطفال الذاتويين العديد من الاضطر ابات السلوكية فى مر احل نمــوهم المختلفة التي تعرقل نموهم النفسي و التربوي. كما أنها تحول بينهم وبــين تمــتعهم بالصحة النفسية الايجابية، ويعد سلوك إيذاء الذات احد الاضطر ابات المنتشرة بــين الذاتويين. (عبد المطلب القريطى وهاله إسماعيل: r ا م ب، r) 
ويعد سلوك إيذاء الــذات Self -injury behavior أحــد الاضــطر ابات المنتشرة بين الذاتويين، حيث يناقش العديد من السلوكيات التكيفية المقبولة اجتماعياً. لذا استقطب جهود الكثير من الباحثين من أجل تفسير أثـــكاله و أنماطــه و أســـبابه المتعددة الأبعاد سعياً لإيجاد السبيل لعلاجه. (Rogers, 2011: 8-10)

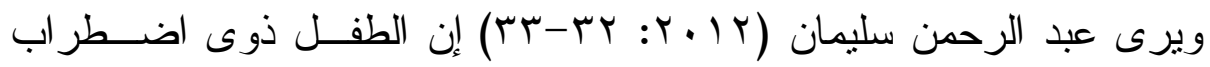

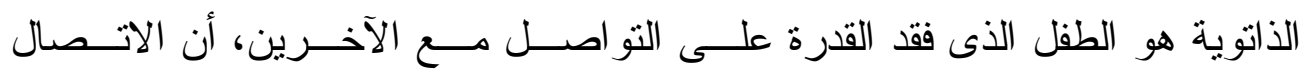

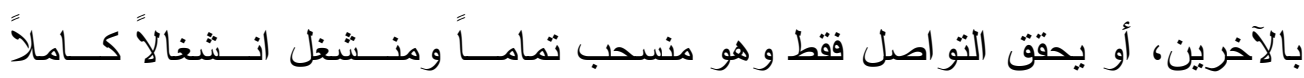

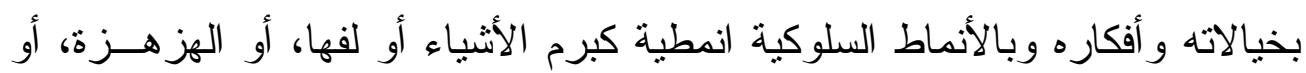

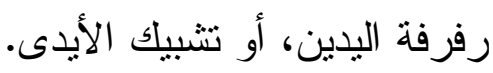

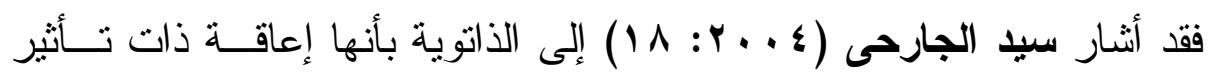
شامل على كافة جو انب النمو تصيب الأطفال خلال سنوات الثناثة الأولى من العمر إلى إلى فتؤدى إلى قصور و اضح فى مهار ات التقاعل الاجتماعي، ومهار ات التو اصل بثقيه اللفظى و غير اللفظى، ومحدودية شديدة فى النشاطات و الاهنمامات بالإضـــافة إلـى السلوكيات المضطربة منل السلوك النمطى، وسلوك إيذاء الذات، ومــن ثــم تكــنـ مشكلة الدر اسة الحالية فى محاولة الإجابة على السؤ ال الرئيس التــالى هــلـ يمكـنـ إعداد مقياس لتقدير سلوك إيذاء الذات لدى عينة من الأطفال الذاتويين.

و على ذللك تتصدى البحثة للتأكد من الخصائص السيكومترية لمقيــاس تقــدير سلوك إيذاء الذات للأطفال الذاتويين و التحقق من صدقه وثباته.

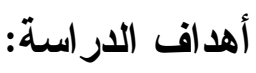
تهدف الدر اسة الحالية إلى:

- إعداد مقياس تقدير سلوك إيذاء الذات لدى الأطفال الذاتويين من سن (1-

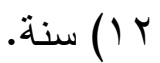


- التأكد من الخصائص السيكومترية لمقياس تقدير إيذاء الذات مــن حيـــث صدقه وثباته.

أهمية الدر اسةة:

تكمن أهمية الدر اسة في الجانب الـذى تتــصدى لـــه، وهــو الكــشف عـن

الخصائص السيكومتزية لمقياس ثقدير سلوك إيذاء الذات لاىى عينــة مــن الأطفــال

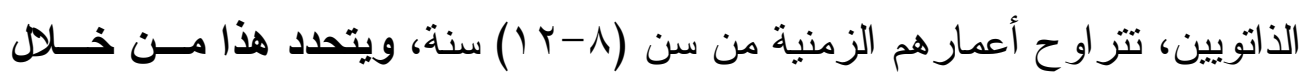
جاتبين أساسينين هما:

الأهمية التظرية: تتحدد الأهمية النظرية من المرحلة العمرية التــي تخـــع لهــا و الجو انب التي تصدت لها وبخاصة فى المجتمعات العربية التى تتسم بالندرة فـى الأبحاث التى تهتم بدر اسة الاضطر ابات النمائية الثاملة وبـــالأخص اضـــر اب الذاتوية. كما تهتم الدر اسة بسلوك إيذاء الذات لدى الأطفال الذاتوبين وما بسببه من مخاطر و أضر ار قد تلحق بالطفل وتهدد حياته المستقبلية، كما تعد هـــذه الدر اســـة محاولة للانتقال من مرحلة وصف العلاقــات و العو امـلـ المرنتطـــة باضـــر اب السلوك إلى مرحلة التذخل العلاجي لتعديل السلوك.

\section{الأهمية التطبيقية:}

ا - تكشف الدر اسة إلى تشخيص سلوك إيذاء الذات و إعداد مقيـــاس لتقــديره

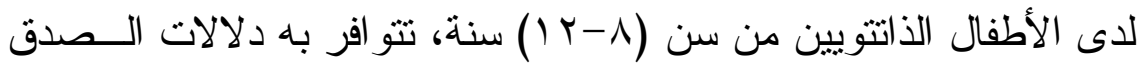

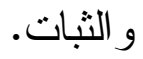

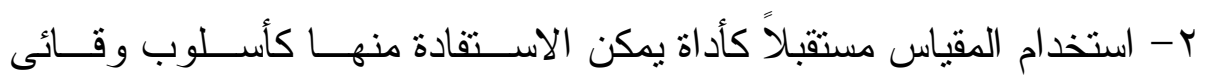
و علاجى لسلوك إيذاء الذات لتلك الفئة من الأطفال. 


\section{تحديد مصطلحات الارسة: \\ • الأطفال الذاتويين:}

هم الأطفال الذين يعانون من اضطر اب نمائى شامل، يظهر فى شــــل زملـــة

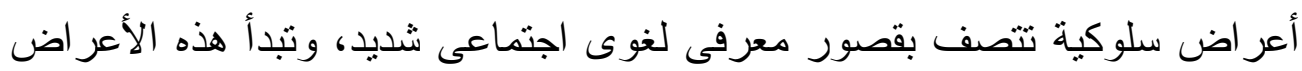

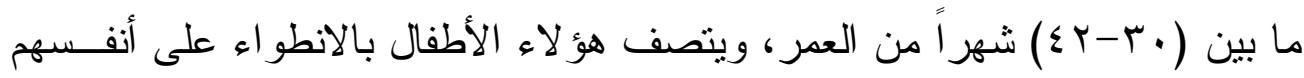

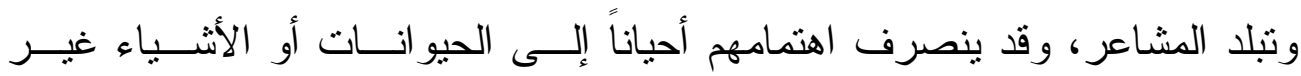
الإنسانية ويصيب ما بين (ع -0) أطفال من كل . . . . . حالة و لادة وبنـسبة أكبـر

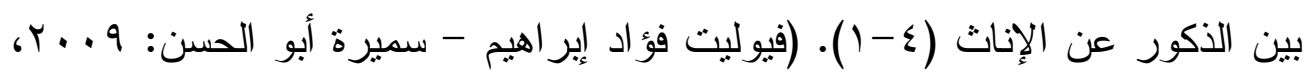
. 10

التعريف الإجرائى للأطفال الأتويين: أنهم الأطفال المعاقون الملتحقون بإحدى

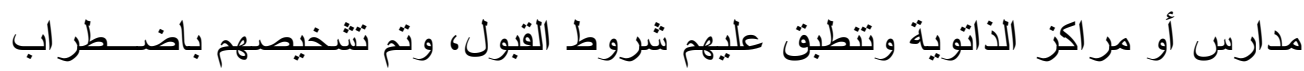
الذاتوية بناء على أدوات النتخيص المعتمدة.

\section{• تعريف سلوك إيذاء الذات SelF Injury Behavior:}

يعرف إيذاء الذات على أنه اضطر اب سلوكى تكرارى غير مرغوب اجتماعيا

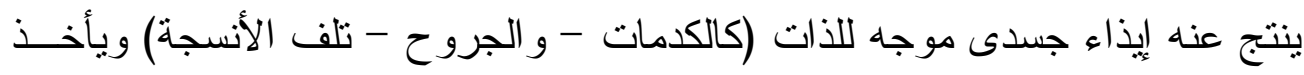

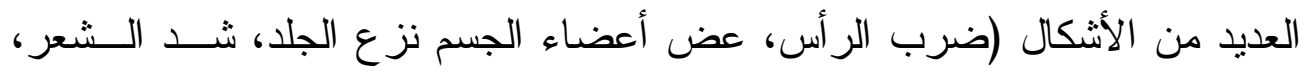
الضغط على العين بشدة) كما أنه ينتشر بين الذاتوية بنسبة مرتفعة، و غالبا ما يكــون لترن

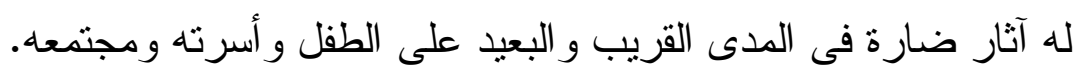

\section{(McCorkl, s 2012)}

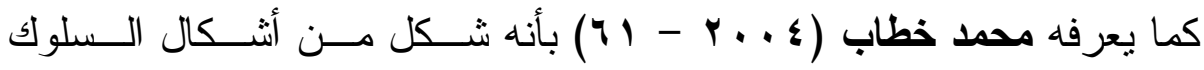
المضطرب و هذا المصطلح يشير إلى استجابات حركية مختلفة تتتهـى بالإيــذاء أو

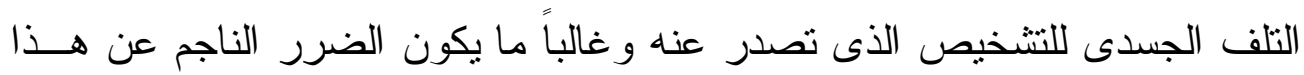


النوع من الاستجابات فورية وتتز اوح فى درجتها وفى شدتها ومداها مما يؤثز تأثنيرً

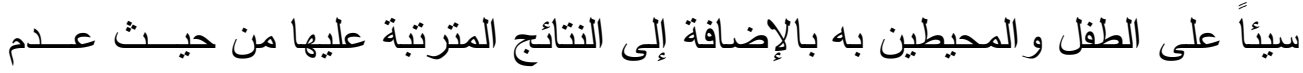
الاستفادة من البر امج التأهيلية و التعليمية و التدرييية و العلاجية.

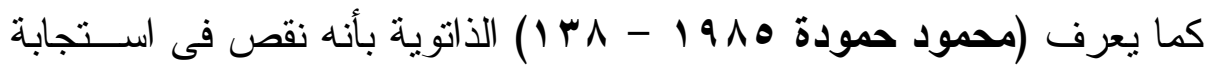

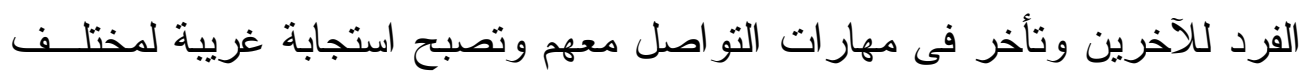
نو احى البيئة، ويحدث هذا قبل عمر ثلاثـين شــــر أ ويقــاوم التغيــر و لا يــرتبط

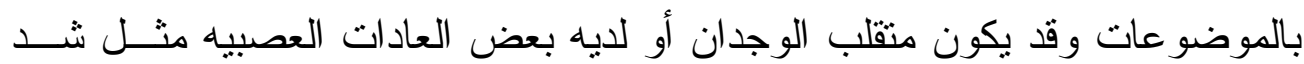
الثعر أو عض نفسه.

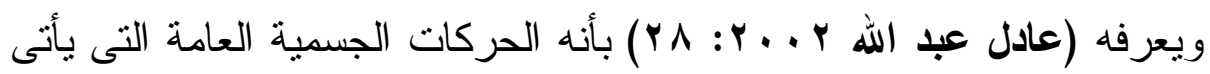
بها الطفل الذاتوى مثل نتبيك الأيدى أو ثثيها أو ضرب الرأس فى الحائط وقد يبدى سلوكيات عدوانية عنيفة أو يجرح أو يؤذى نفسه، كما يفتقر بــشكل و اضــح إلـى الـى

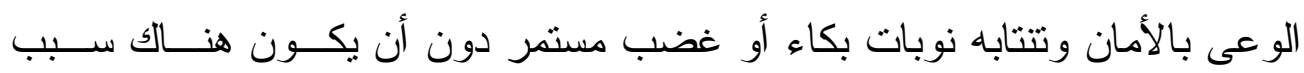

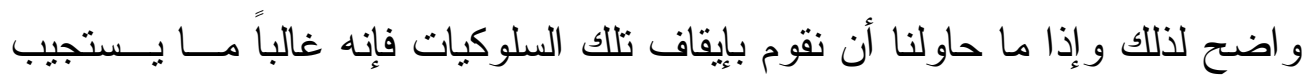
لذلك بنوبة مز اجية تتمنل فى أغلب الأحيان فى البكاء و الصر اخخ وتخبيط باليد فى أى شيء ثابت أمامه إلى جانب الغضب. التعريف الإجرائى لسلوك إيذاء الأت:

على أسـاس أنه سلوك مضطرب يمارسه الطفل الذاتوى. ويترتب عليه إلحــاق

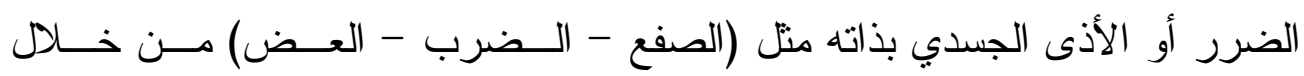

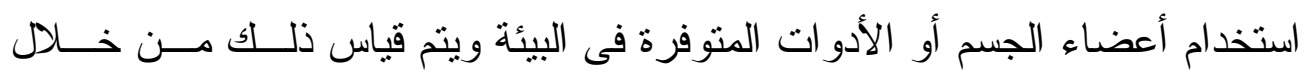
الدرجة التي يحصل عليها الطفل الذاتوى في قائمـــة تقــدير ســلوك إيــذاء الــذات المستخدمة فى الدر اسة. 
سعت الدر اسة إلى التحقق من فاعلية برنامج علاجي باللعب لخفـ درجــة

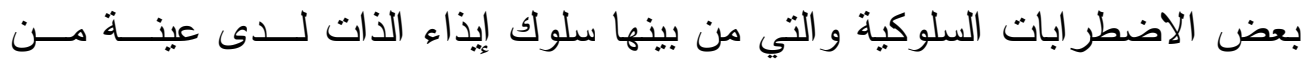

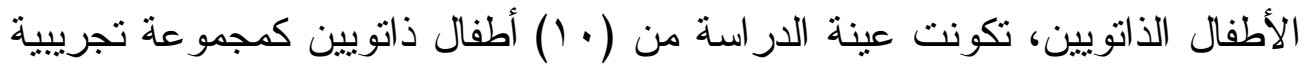

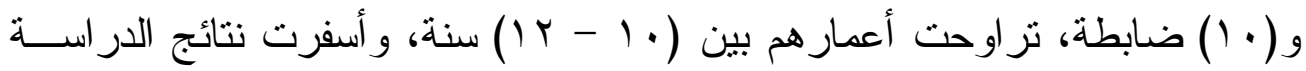

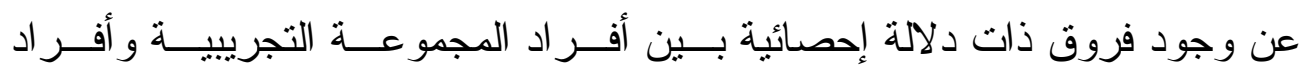

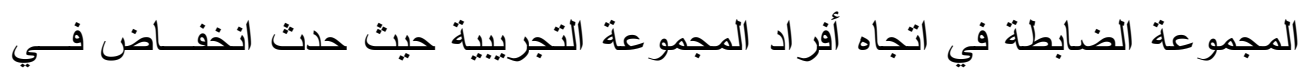
حدة الاضطر ابات السلوكية ومنها سلوك إيذاء الذات.

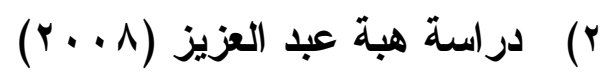

تهدف الدراسة إلى تقليل سلوك إيذاء الذات باستخدام فنيات تعـديل الـسلوك

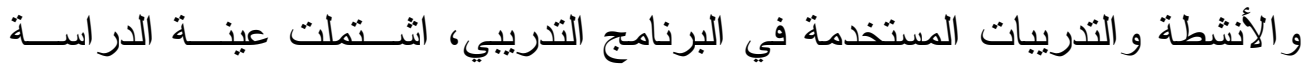

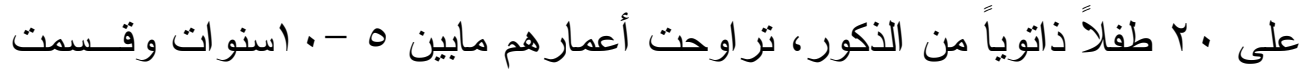
العينة إلى مجمو عنتين إحداهما تجرييية و الأخرى ضابطة، استخدمت الباحثة الـــليل

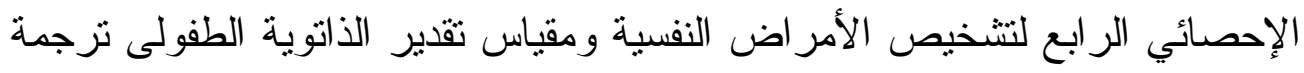

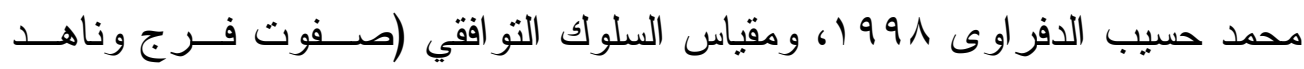

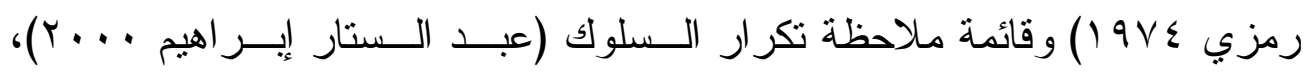

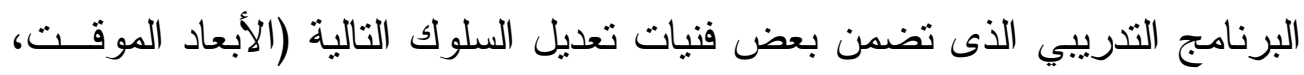

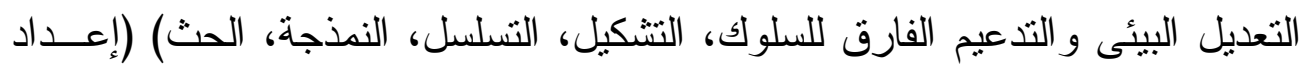

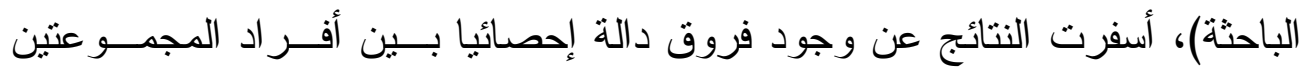
التجريبية و الضابطة قبل نطبيق البرنامج التدريبى فى كل من المتغيــر ات الوســيطة

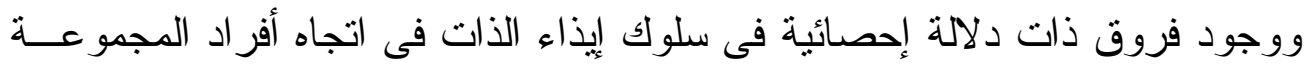




\section{r) ب در اسة سوارس وفانست وهاريسون:}

\section{(Soares, Vannest \& Harrison. 2009)}

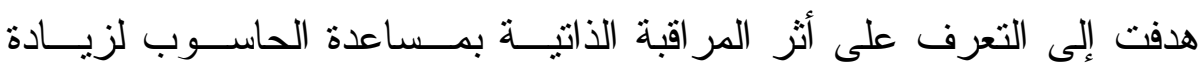

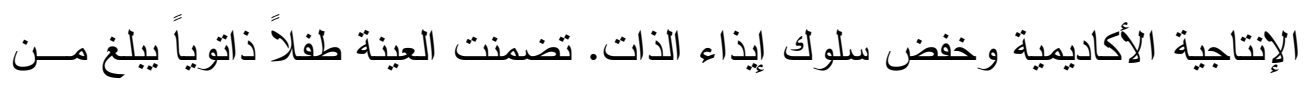
العدر با سنة ويمارس هذا السلوك بمعدل مرتقع عندما تقــوم المعلمـــة بإعطائـــهـ التعليمات اللازمة لا داء الأنشطة و الو اجبات الأكاديمية المطلوبة منه، استخدم فـي بـي الدر اسة التصميم العكسي (ABAB) ومقياس سلوك إيذاء الذات، و استمارة ملاحظة

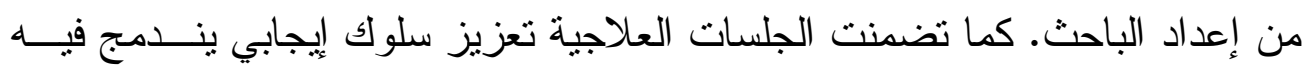
الطالب و استبداله بإيذاء الذات، وذلك من خلال برنامج في الحاسوب يقــوم الطفــلـ بأداء كافة المتطلبات الأكاديمية وو اجباته المدرسية وفى حال إتماهها بشكل صــحيح يمنح تعزيز يتمنل في اختياره الصور الكرتونية للشخصيات المفضلة بالنـسبة لــه، أوضحت فاعلية المر اقبة الذاتية في خفض سلوك إيذاء الذات وتحسـسين الــسلوكيات التكيفية المناسبة لدى الطفل الذانوى الذي قام بتعميمها خارج الفصل إلى كافة البيئـة المدرسية، كما تبين أن هناك ارتفاعاً ملحوظاً فى معدل انتباه الطفل الذاتوى بالفصل الدر اسي أثناء قيامه بالعديد من الأنشطة الأكاديمية.

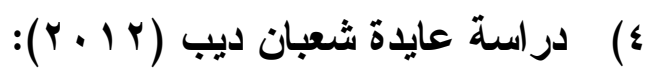

هدفت الدر اسة إلى التحقق من فاعلية برنامج تدريبي فــي تنميــة مهــار ات التواصل والتفاعل الاجتماعي في خفض سلوك إيذاء الأت لاءى الأطفال الأتويين. طبقت على عينة قو امها ـ طفلا ذاتوياً لديه قصور في المهار ات المذكورة، وقد تم تقسيمهم إلى مجمو عتين بالتساوي إحداهما تجريبية و الأخرى ضـــابطة، اســتخدمت

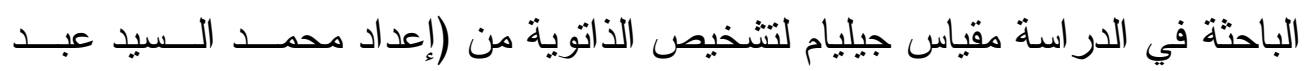

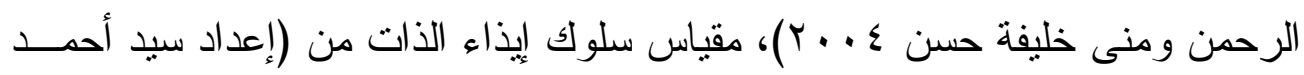

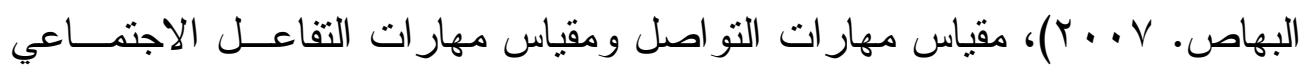


و البرنامج التذريبي من (إعداد الباحثة)، وتوصلت النتائج إلى وجــود فــروق دالـــة

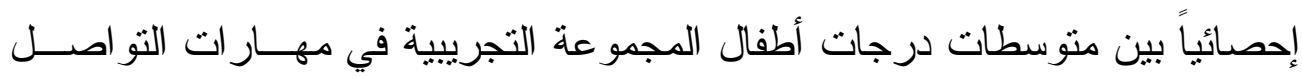
و التقاعل الاجتماعي وسلوك إيذاء الذات فى القياس القبلى و البعدى لــصـالح القيــاس البعدى و أظهرت أيضا وجود فروق دالة إحصائيا بين متوسطات درجــات الأطفــال بالمجمو عتين التجريبية و الضابطة فى مهار ات التو اصل و التفاعل الاجتماعي وسلوك

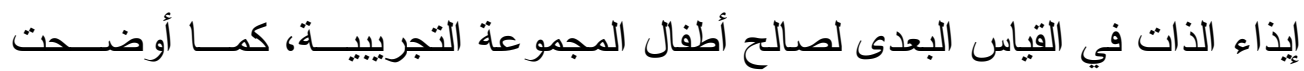
النتائج عدم وجود فروق ذات دلالة إحصائيا بين درجات أطفال المجموعة التجريبية في مهار ات التو اصل و التفاعل الاجتماعي وسلوك إيذاء الــذات بالقياســين البعـدى و التتبعى. در اسة مصطفى عارف فاهم محمد (0 ( ب): $(\bullet$ هدفت إلى التحقق من فاعلية البرنامج باستخدام المدخل الحس حركى فــى تتميــة التكامل الحسي وخفض سلوك إيذاء الذات لدى الأطفال الذاتويين. تكونت عينة الدر ســـة من r ا طفلاً ذاتوياً تتز اوح أعمار هم بين ع - ـ ـ سنوات ويتم تقسيمهم إلى مجموعتين مجموعة تجريبية ومجموعة ضابطة، و استخدم الباحث المــنهج التجريبـى، ومقيــاس

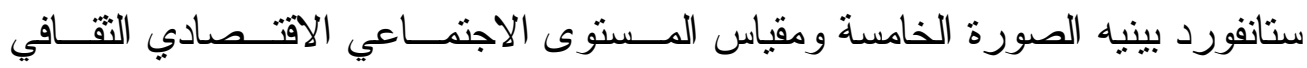
للأسرة المصرية إعداد محمد بيومي خليل (Y . . F) ومقياس تقدير ذاتوية الطفولة إعداد

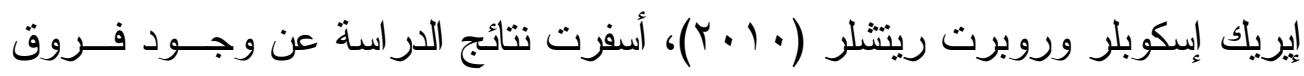

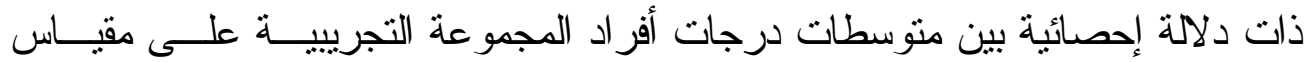
التكامل الحسي في اتجاه التطبيق البعدى، وجود فروق ذات دلالة إحصائية بــين أفــر اد المجموعة التجرييية و المجموعة الضابطة على مقياس سلوك إيذاء الذات بعـد تطبيــق البرنامج في اتجاه المجموعة التجريبية. 


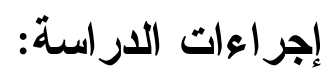

• أولاً: منهج الار اسة: تعتمد الباحثة على المنهج الوصفى السيكومترى بحدوده المعروفة للار اسة الحالية.

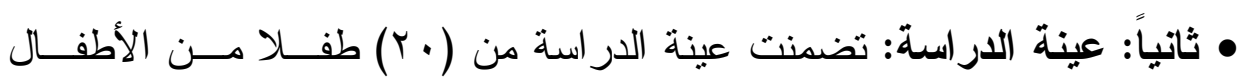

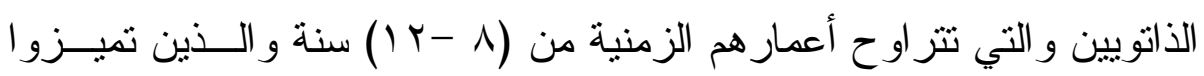

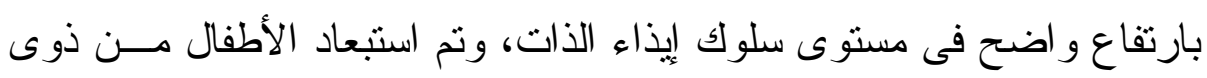

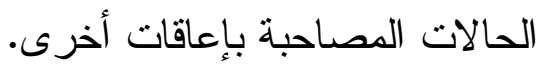
تعرض الباحثة خطوات تصميم مقياس سلوك إيذاء الــذات لــدى الأطفـــال الأتويين: تم إعداد مقياس سلوك إيذاء الأت بالخطوات التالية: 1- الاطلاع على الكتابات النظرية و التراث السيكولوجي الخاصـــة بمهــار ات التو اصل اللفظي للأطفال عامة، و الأطفال الذاتوبين خاصة. r- قامت الباحثة بإجر اء مستح للبحوث و الدر اســات العربيـــة و الأجنبيــة ذات العلاقة بالمقياس المر اد تصميمه حيث تم الاطلاع على: - مقياس الاضطر ابات السلوكية إعداد: محمد محمود خطاب (ع . . ץ). - مقياس تقييم الأعر اض السلوكية لاضطر اب الذاتتية إعداد: أيمن فــرج $\cdot(r \cdot T)$ - مقياس سلوك إيذاء الذات إعداد: سحر ربيع (9 . . ب).

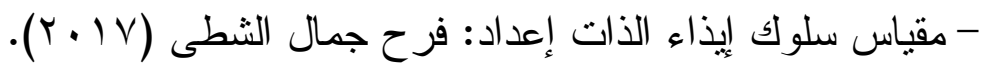
ولقد أفادت هذه المقاييس الباحثة في التعـرف علـى المؤشــرات الرئيـسـة

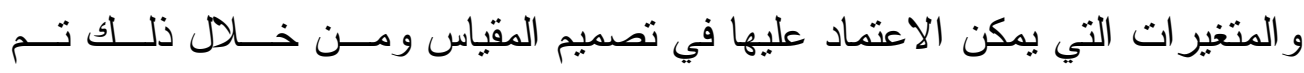
التوصل إلى عدد من الأبعاد الرئيسية الخاصة بايذاء الذات والتى تتمثل فى: 
r- بعد ذلك قامت الباحثة بإجر اء در اسة استطلاعية مبدئية بإجر اء عـدد مــن

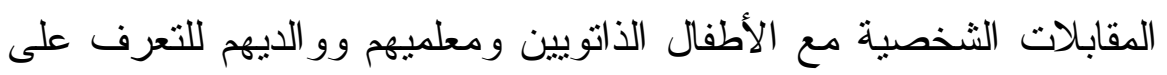
مظاهر سلوك إيذاء الذات.

ع - تم التحديد الإجر ائى لكل بُعد، ثم صياغة مجموعة من العبار ات التى يمكن

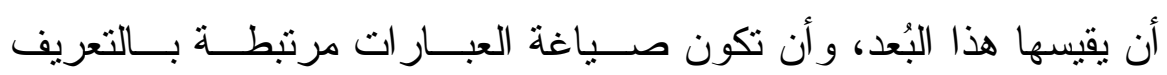
الإجر ائى فى صورة مبسطة وذات لغة مفهومة مع تحديد المعنى بدقة. 0- ثم قامت الباحثة بالخطو ات التالية: - تحديد الهدف العام من المقياس في التعرف على سلوك إيذاء الذات لدى الأطفال الذاتوبين. - تحديد أبعاد مقياس سلوك إيذاء الذات إجر ائياً. - تصميم عدد من العبار ات التي تنتاسب مع التعريف.

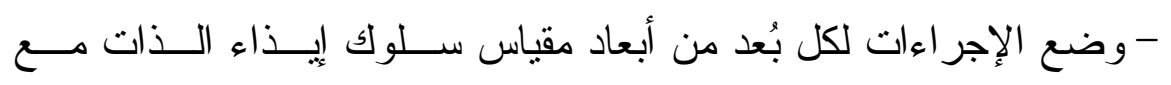
الاستعانة ببعض العبار ات من المقاييس السابق ذكر ها.

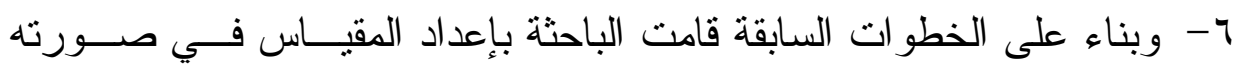

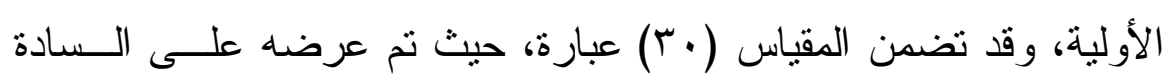

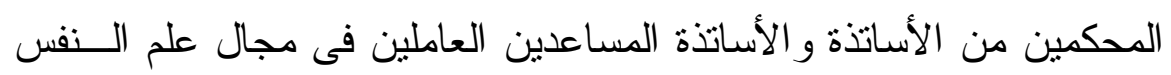
و الصحة النفسية لإبداء الر أى فى عبار ات المقياس من حيث:

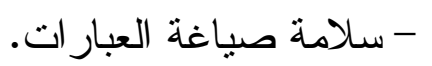


- مدى مناسبة العبار ات للأطفال عينة الدر اسة. - إضافة العبار ات التي يرون أنها تكمل الهدف من المقياس. وقد أسفر رأى المحكمين عن سلامة جميع عبـار ات المقبــاس وارتباطهــا بالأبعاد والبنود والمعنى المراد الوصول إلى قياسه. V- وبعد الانتهاء من الصورة الأولية للمقياس أصبحت صورته النهائية تتكون من ( • ب) عبارة موزعة على ثلاث أبعاد كالتالى: - البعد الأول: الإيذاء البذنى: هو قيام الطفل الذاتوى بإيقاع الأذى البــنى

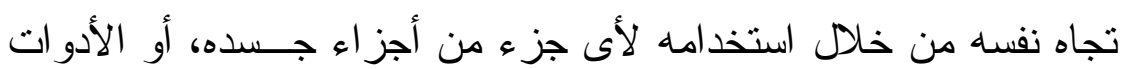
المتوفرة فى بيئته، ويتكون هذا البعد من (T ا) عبارة ويتضمن العبار ات

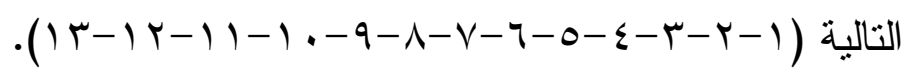

- البعد الثانى: نوبات غضب شديدة: وهى تعبر عن المشاعر و الانفعالات السلبية التى تعبر عن إيذاء الطفل الذاتوية لذاته، لافتقاره للإثارة فى بيئة غير مثثيرة، ويتكون هذا البعد من (9) عبار ات ويتضمن العبار ات التالية

$$
.(r r-r)-r \cdot-19-11-1 v-17-10-1 \varepsilon)
$$

- البعد الثالث: تناول (أكل) أثثياء غير صالح: وهى عبارة عـن تتــاول

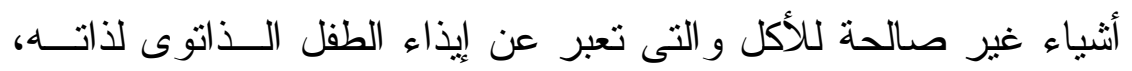

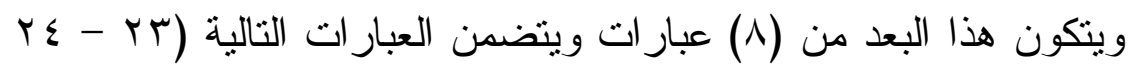

$$
\cdot(r \cdot-r q-r \Lambda-r V-r q-r O-
$$

1 - قد وضع مدر ج للإجابة ليضم ثناث اختيار ات من (دائماً، أحياناً، أبداً) وفق مدرج ليكرت الثلاثى وتعطى درجاته (ب، ب، ( ) على التو الى. 


\section{نتائج الدراسة:}

صدق مقياس سلوك إيذاء الذات للأطفال الذاتويين:

ا - صدق المحكمين: قامت الباحثة بعرض المقياس على مجموعة مــن الأســاتذة

المتخصصين فى مجال الصحة النفسية والتزبية الخاصة، بلــنع عــددهم ( ( )

محكمين وبناء على توجيهاتهم تم تعديل بعض العبــار ات، و الجــدول التــالي

يوضع معاملات الاتفاق بين المحكمين لعبار ات المقياس.

جدول (1)

معاملات الاتفاق بين المحكمين لعبارات مقياس سلوك إيذاء الذات للأطفال الذاتويين

\begin{tabular}{|c|c|c|c|c|c|c|c|c|}
\hline نالفبة & عرات الاتفاق & رالعبارة & ناتفبة & عرات الاتفاث & العبارة & نسبة & عرات الاتفاق & رقبارة \\
\hline$\% 9$. & 9 & r & $\% 1 \ldots$ & 1. & 11 & $\% 1 \ldots$ & 1. & 1 \\
\hline$\% 1 \ldots$ & 1. & rr & $\% 9$. & 9 & ir & $\% q$. & 9 & $r$ \\
\hline$\% \wedge$ & $\Lambda$ & $r r$ & $\% 1 \ldots$ & 1. & ir & $\% 1 \ldots$ & 1. & $r$ \\
\hline$\% 1 \ldots$ & 1. & $r \varepsilon$ & $\% 9$. & 9 & $1 \varepsilon$ & $\% 1 \ldots$ & 1. & $\varepsilon$ \\
\hline$\% q$. & 9 & ro & $\% 1 \ldots$ & 1. & 10 & $\% q$. & 9 & 0 \\
\hline$\% q$. & 9 & Y & $\% \wedge$. & $\wedge$ & 17 & $\% \wedge$ & $\Lambda$ & 7 \\
\hline$\% 1 \ldots$ & 1. & $r v$ & $\% 1 \ldots$ & 1. & iv & $\% 1 \ldots$ & 1. & V \\
\hline$\% 9$. & 9 & $r \wedge$ & $\% 1 \ldots$ & 1. & 11 & $\% \wedge$ & $\Lambda$ & $\Lambda$ \\
\hline$\% 9$. & 9 & rq & $\% q$. & 9 & 19 & $\% 1 \ldots$ & 1. & 9 \\
\hline$\% \wedge$ & $\Lambda$ & r. & $\% 9$. & 9 & $r$. & $\% 1 \ldots$ & 1. & 1. \\
\hline
\end{tabular}

يتضتح من الجدول السابق أن نسب اتفاق السادة المحكمــين علــى عبــار ات

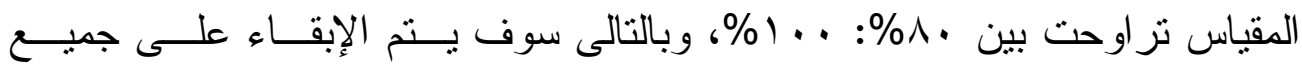
عبار ات المقياس. 


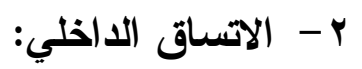

تم إيجاد التجانس الداخلي للمقياس عن طريق حساب معامل الارتبـــاط بـين درجات أفر اد العينة على كل عبارة و الدرجة الكلية للبعد الذي تتتمي إلبه.

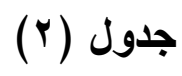

معاملات الارتباط بين درجة كل عبارة والدرجة الكلية للبعد الأي تتثمي إليه

\begin{tabular}{|c|c|c|c|c|c|}
\hline \multicolumn{2}{|c|}{ غتاول (أكل) أشياء } & \multicolumn{2}{|c|}{ نوبات الغضب } & \multicolumn{2}{|c|}{ إيذاء الذات } \\
\hline معامل الارتباط & رقم العبارة & معامل الارتباط & رقم العبارة & معامل الارتباط & رقم العبارة \\
\hline$\cdot, \varepsilon \cdot \Lambda$ & $r r$ & .017 & $1 \varepsilon$ &., 011 & 1 \\
\hline$\cdot, \leqslant \diamond V$ & $r \leq$ & $\cdot, \leqslant \wedge \wedge$ & 10 & & $r$ \\
\hline .,OYY & ro & $\cdot, \leqslant 9 \vee$ & 17 &., $01 \leqslant$ & $r$ \\
\hline$\cdot, \leqslant V \leqslant$ & Y & $\cdot, 0, Y$ & iv & $\cdot, \leqslant V Y$ & $\varepsilon$ \\
\hline.,$\leqslant 19$ & $r v$ & •, $\leqslant$ «q & 11 & $\cdot, \leqslant q \mu$ & 0 \\
\hline •,or & $r \wedge$ & $\cdot, \leqslant 90$ & 19 & $\cdot, \leqslant \wedge r$ & 7 \\
\hline$\cdot, \leqslant \leqslant \mu$ & rq &., 011 & $r$. & $\cdot, \leqslant 9 \vee$ & v \\
\hline \multirow[t]{6}{*}{$\cdot, 0, r$} & $r$. & $\cdot, \leqslant \wedge$. & YI & $\cdot, \varepsilon r V$ & $\Lambda$ \\
\hline & & $\cdot, \leqslant \leqslant 9$ & $r r$ & $\cdot, \leqslant \wedge q$ & 9 \\
\hline & & & & $\cdot, \varepsilon \leqslant V$ & 1. \\
\hline & & & &., 019 & 11 \\
\hline & & & & $\cdot, \leqslant \vee 7$ & ir \\
\hline & & & &., 0.1 & ir \\
\hline
\end{tabular}

$$
(\varepsilon \cdot=\dot{0})
$$

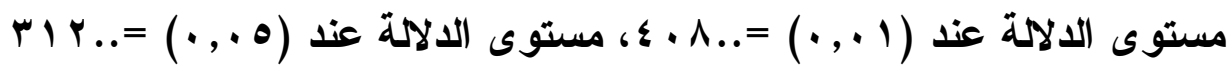


يتضح من الجدول السابق أن جميع قيم معاملات الارتباط دالة إحصائيا عنــد

$$
\text { مستوى دلالة (1 (. . ). }
$$

ثم قامت الباحثة بحساب معاملات الارتباط بين الدرجة الكلية لكل بعـد مــن أبعاد المقياس و الدرجة الكلية للمقياس، و الجدول التــالي يوضــح نتــائج معــاملات الارنباط.

\section{(r) جدول}

الاتساق الاخلي لأبعاد مقياس سلوت إيذاء الذات للأطفال الذاتويين $(\varepsilon \cdot=\dot{0})$

\begin{tabular}{|c|c|}
\hline معاملات الارتباط & الأبعاد \\
\hline • & إيذاء الذات \\
\hline, $0 \vee 9$ & نوبات الغضب \\
\hline$\bullet, 0 \leq 1$ & تتاول (أكل) أثياء غير صالحة \\
\hline
\end{tabular}

يتضح من الجدول السابق أن جميع قيم معاملات الارتباط دالة إحصائيا عنــد

$$
\text { مستوى دلالة (1 (, •). }
$$

• ثبات مقياس تقدير سلوك إيذاء الذات للأطفال الذاتوبين:

تم حساب ثبات المقياس تم استخدام طريقة ألفا - كرونباخ، وطريقــة إعــادة تطبيق المقياس على نفس الأفراد الذين تم التطبيت الأول عليهم، وذلك بفاصل زمني قدره أسبو عين بين التطبيقين. 
قيم معاملات الثبات بطريقة ألفا - كرونباخ وطريقة إعادة تطبيق المقياس $(\varepsilon \cdot=\dot{0})$

\begin{tabular}{|c|c|c|}
\hline إعادة التطبيق & ألفا كرونباخ & الأبعـــــــاد \\
\hline$\cdot, \wedge M_{I}$ & $\cdot, \Lambda \mid r$ & إيذاء الذات \\
\hline$\cdot, \Lambda \cdot 9$ & $\cdot, \vee \vee 91$ & نوبات الغضب \\
\hline$\cdot, \wedge r r$ & $\cdot, \wedge r q$ & تتاول (أكل) أثياء غير صالحة \\
\hline$\cdot, \wedge \leq \vee$ & $\cdot, \wedge \mu \wedge$ & الكلية \\
\hline
\end{tabular}

يتضح من الجدول السابق أن جميع قيم معاملات الثبات مرتفعة، مما يجعلنـا

نثق فى ثبات المقياس.

طريقة التطبيق و التصحيح، يتم تطبيق هذا المقياس على الأطفــال الــذاتوبين وفقاً لتقدير المعلم، وقد قامت الباحثة بمقابلة معلمى هؤلاء الأطفال ويشرح لهم كيفية تطبيقه و اختيار الإجابة المناسبة من إحدى الخيار ات من مدرج الإجابـات (تـدرج

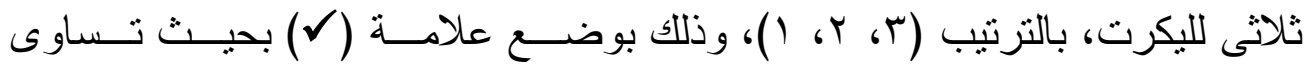

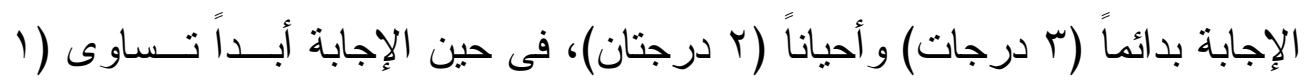

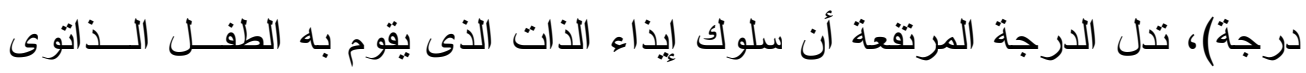
مرتفع، و العكس على ذلك تدل الدرجة المنخفضة أن السلولك لديه منخفض، عند هذا

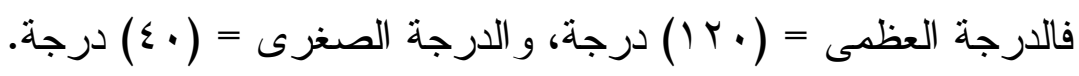
الأسلوب الإحصائى المستخدم فى الار اسة: - - المتوسطات الحسابية. 


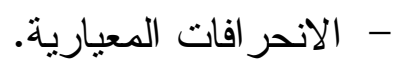

- معامل ارتباط بيرسون للتحقق من صدق الاتساق الداخلى لمقياس ســلوك إيذاء الذات للأطفال الذاتويين. - ومعامل الفاكرونباخ لحساب ثبات مقياس سلوك إيذاء الذات.

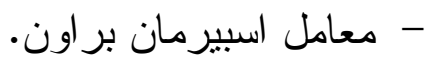

Man - الأساليب الإحصائية اللابار امترية وهى (اختبــار مــان ويتـى .(Whitney - و اختبار ويلكسكون wilcocxon Test. الخطو ات الإجرائية للار اسة:

- وضـع عبار ات المقياس تحت كل بُعد من الأبعاد وعرض صورته الأوليـــة على عشرة محكمين من الأساتذة المحكمين المتخصــصين فــى الــصحة النفسية و التزبية الخاصة بجامعتى عين شمس و القاهرة. - اختيار عينة عشوائية من الأطفال الذاتويين من سن (1- I ( سنة لـديهم ارتفاع و اضح فى سلوك إيذاء الذات وذلك حسب التقارير الموضوعة فـى ملفاتهم. - تطبيق المقياس بصورته الأولية على عينة الدراسة فى مدرســة التربيــة الخاصة. - رصد الاستجابات من البيانات تمهيداً لإدخالها إلى الحاس الآلى. - معالجة البيانات الإحصائية وفقاً للأساليب الإحصائية المحددة. - كتابة نتائج التحليل الإحصائى لصدق وثبات المقياس. 
- التوصل إلى الصورة النهائية لمقياس سلوك إيذاء الذات للأطفال الــذاتويين

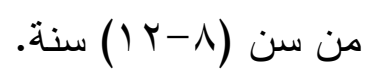

\section{تقسير نتائجج الار (سةة:}

تبين من النتائج أن مقياس سلوك إيــذاء الــذات للأطفــال الــذاتوبين بتـسم بالخصائص السيكومترية (بالصدق و الثبات) مناسبين لأغر اض هذه الدر اســة، لــذا لـا يمكن استخدامه فى الدر اسات النفسية و التربوية التى تنتاول خفض سلوك إيذاء الذات

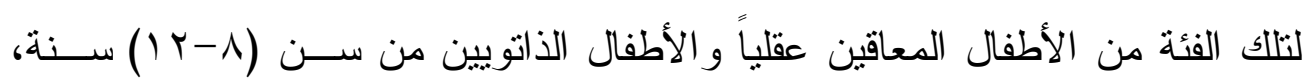
لتقديم الخدمات النفسية و التزبوية و العلاجية.

فى ضوء الخصائص السيكومترية لمقياس تقدير سلوك إيذاء الأت تتصدى الباحثة لبعض التوصيات التزبوية، وهى كما يلى:

- - يمكن الاستفادة من مقياس سلوك إيذاء الذات كأداة مقننة لقياس سلوك إيـذاء الذات للأطفال الذاتويين.

- تدريب المعلمين و الأخصائيين على تطبيق مقياس سلوك إيذاء الذات للأطفال

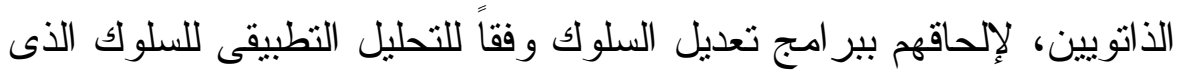
يهدف إلى خفض سلوك إيذاء الذات وتحقيق جودة الحياة لهم. - - التزكيز على استخدام الفنيات السلوكية غير التنفيرية منل (الإقــصاء عـن

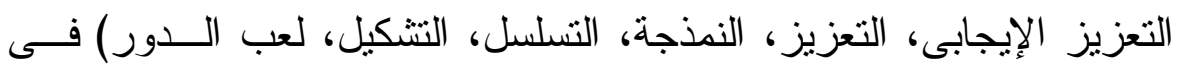
علاج سلوك إيذاء الذات للأطفال الذاتويين. - لفت أنظار (الو الدين و المعلمين) للتغلب على سلوك إيذاء الذات. - - إدر اج بر امج التحليل التطبيقى للسلوك التى تهدف إلى خفض ســلوك إيــذاء

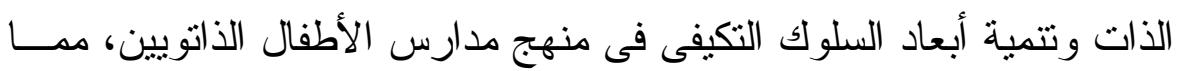
يساعدهم على الاندماج فى المجتمع بشكل طبيعى. 


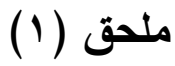

مقياس سلوك إيذاء الذات للأطفال الأتويين

من وجهة نظر وتقدير المعلم

(إعداد الباحثة)

إثراف

د/محمد محمود عبد النبي

أ. أد/ فيوليت فؤاد إبر اهيم

تعليمات المقياس

صمم هذا المقياس لغرض البحث العلىى، وهدف إلى قياس سلوك إيذاء الذات

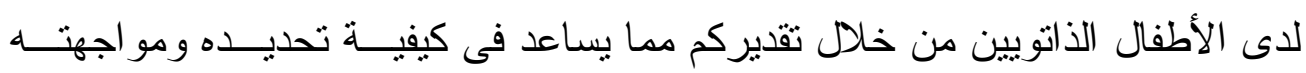

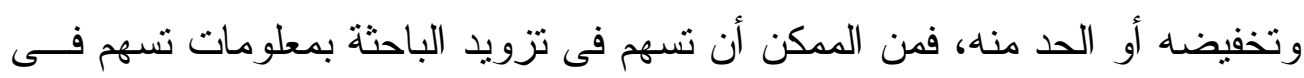
تطوير الخدمة التربوية لهؤلاء الأطفال.

فى الصفحات الثالية نجد مقياس تقدير سلوك إيذاء الذات الذى يحتــوى علىى

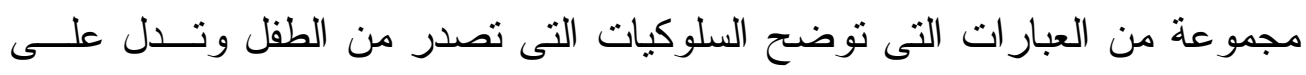

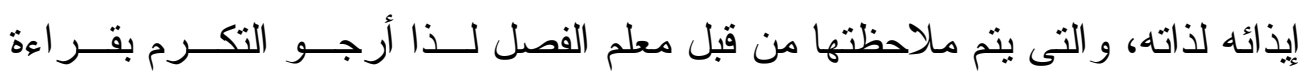

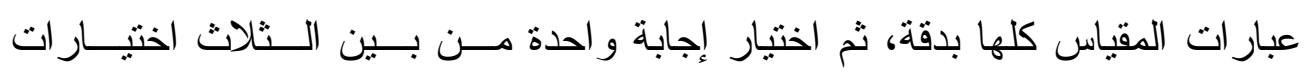

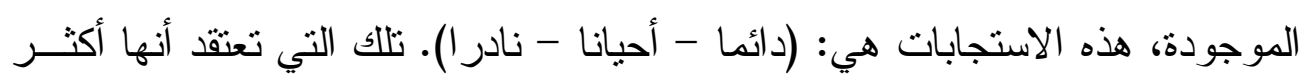

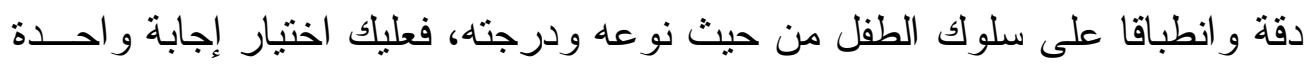

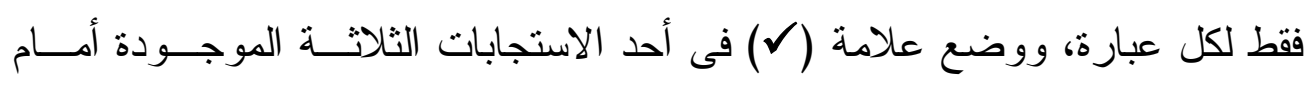
العبارة التي ترى أنها تتطبق على سلوك الطفل.

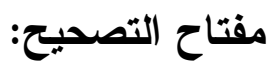

\author{
يتم التصحيح عن طريق أعطاء: \\ - ثلاث درجات (ץ) للإجابة (دائماً).
}




$$
\begin{aligned}
& \text { - در اجتان (Y) للإجابة (أحيانا). } \\
& \text { - درجة (1) للإجابة (نادر ا). }
\end{aligned}
$$

\begin{tabular}{|c|c|c|c|c|}
\hline نادراً & أحياناً & دائما & 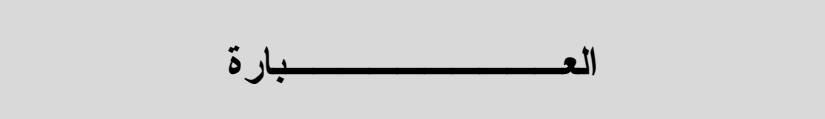 & رقم \\
\hline & & & يضرب نفسه ويؤذيها & 1 \\
\hline & & & يشّد شعر رأسه بشدة & r \\
\hline & & & بعض بذه & $\mu$ \\
\hline & & & كثير الصر اخ & $\varepsilon$ \\
\hline & & & يضرب رأسه بالحائط بشكل مؤذ & $\bullet$ \\
\hline & & & يضرب رأسه بقبضة يده & 7 \\
\hline & & & يتسلق الأشباء المرتفعة & V \\
\hline & & & يضغط على عينيه بأصبعه بشده & $\Lambda$ \\
\hline & & & يشت أذنه بشكل قاس & 9 \\
\hline & & & يحك جسده بشكل مؤذ حتى النزيف & 1 . \\
\hline & & & يعض على لسانه بشدة & 11 \\
\hline & & & يقوم بثتى أصابعه للخلف و العض علبها بشدة & ir \\
\hline & & & يقوم بشد أذنه بشكل متكرر & 1 \\
\hline & & & كثير الصر اخ ونوبات الغضب لا سباب غير ظاهرة & $1 \varepsilon$ \\
\hline & & & 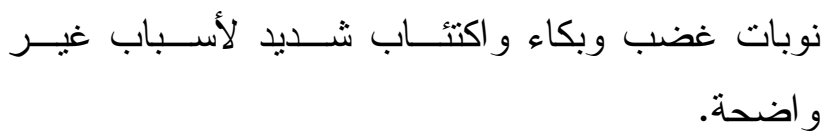 & 10 \\
\hline & & & يغضب ويثور عند حدوث تغير فى البيئة. & 17 \\
\hline & & & سريع الغضب إذا وجه إليه اللوم. & 18 \\
\hline
\end{tabular}

مقياس سلوك إيداء الذات لاى الأطفال الذاتويين 


\begin{tabular}{|c|c|c|c|c|}
\hline 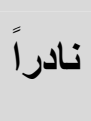 & 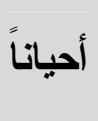 & دائما & 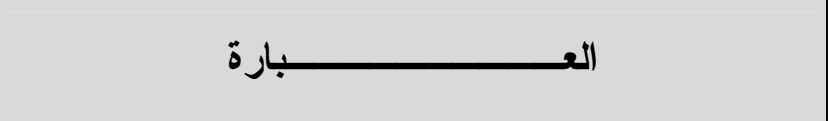 & | - مقرم \\
\hline & & & هياج شديد إذا لم تلبى له طلبه & 11 \\
\hline & & & ضحك وصر اخ غير مناسب للموقف. & 19 \\
\hline & & & غير مفهوما يغضب لا يسنطيع ضبط سلوكه وينطــق بكلمــات & $r$. \\
\hline & & & عند نوبات الغضب يلقى بجسمه على الأرض دون وعى & M \\
\hline & & & عند الغضب يجرى بعيدا عندما يقترب منه أحد. & rr \\
\hline & & & يعلق الأشياء بفمه بشكل متكرر & $r r$ \\
\hline & & & يلعب بريقه(لعابه) بشكل متكرر & $r \varepsilon$ \\
\hline & & & مره أخرى سلوك وضع الأصبع فى أنفه ثم الانتقال إلى فـــهـ & ro \\
\hline & & & يضع الأشياء و اللعب الصغيرة فى فمه & rq \\
\hline & & & يأكل من على الأرض أو من سلة القمامة & rv \\
\hline & & & يتقيأ متعددا & r^ \\
\hline & & & يأكل مواد غير صــالحة (تـراب - مناديـلـل - ورق - & rq \\
\hline & & & قضم الأشياء الحادة والصلبة & 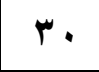 \\
\hline
\end{tabular}




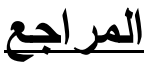

أولاً: المراجع العربية:

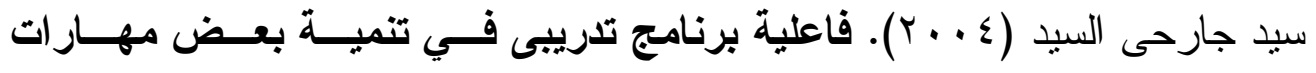

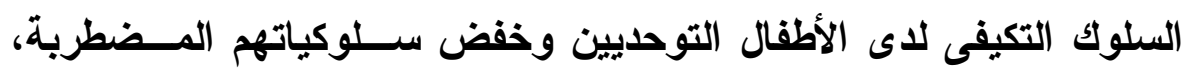
رسالة ماجستير ، كلية نربية، جامعة عين شمس.

عادل عبد الله محمد (Y . . r). الأطفال الذاتويين دراسات تثخيــصية وبرامجيـة،

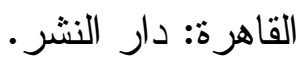

عادل عبد الله محمد (ع ( ب). مدخل إلى اضطراب التوحد النظريــة والتـشخيص وأساليب الرعاية، القاهرة: الدار المصرية اللبنانية.

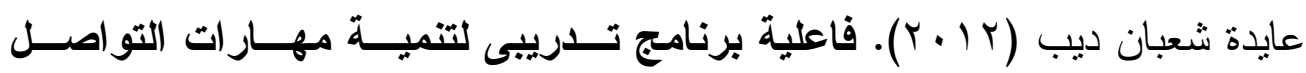

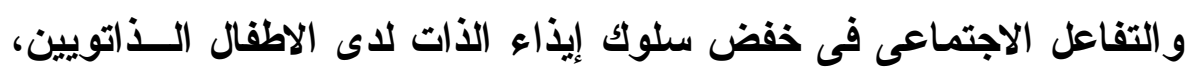
القاهرة: مجلة الطفولة و التربية، المجلد ؟. العدد r I. عبد الرحمن سليمان (Y Y r Y). معجم مصطلحات اضطر اب التوحد، إنجليزى عربى - عربى إنجليزى، القاهرة: مكتبة الأنجلو المصرية.

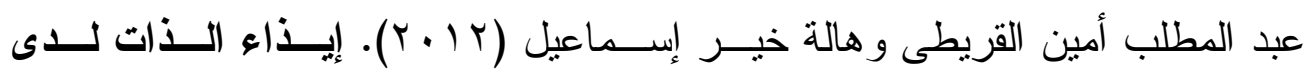

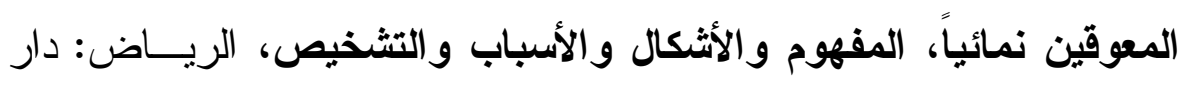

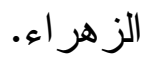

فيوليت فؤاد إبر اهيم، سميرة أبو الحسن عبد الـسلام (9 . +؟). مقيــاس تـشخيص

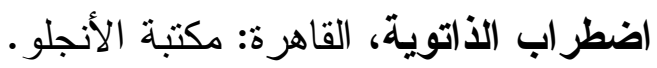




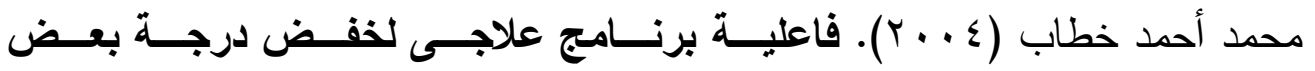
الاضطر ابات السلوكية لاى عينة من الأطفال التوحديين، رسالة دكتهـور اه، معهد الدر اسات العليا للطفولة، جامعة عين شمس.

محمد أحمد خطاب (0 . . ب). سيكولوجية الطقل التوحدى، تعريفها - تـصنيفها أعراضها - تشخيصها - أسبابها - التدخل العلاجى، عمان، دار التقافة. محمود عبد الرحمن حمودة (910 (1). الطب النفسى، القاهرة: دار الفجالة. مصطفى عارف فاهم محمد (0 10 ب). فاعلية برنامج باستخدام المدخل الحسحركى فى تنمية التكامل الحسى وخفض سلوك إيذاء الأات للأطفال الأتويين.

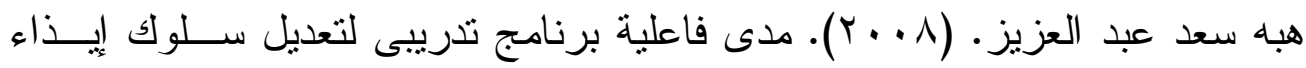
الذات لاى الأطفال الذاتويين، رسالة ماجستير، كلية الآداب، جامعــة عـين عـين شمس، جمهورية مصر العربية.

ثانباً: المراجع الأجنبية:

Edelson, S.,\&Johnson, J. (2016) Self - Injury Medicine and Society: Authentic Bodies. United Kingdom: Springer Nature Publishing.

Rogers, SJ.(2009).What are Infant Siblings Teaching us about Autism inInfancy ?Autism Res, Vol. (2), No. (3) PP.125.

McCorkl, S. (2012) Decreasing self - injurious Behaviors in children with Autism spectrum Disorders. Journal of special Education, Vol. 1, No 3, PP-1-15.

Baghdadi, A. Pacal, C. Grisi, S. \& Aussilloux, C. (2003) Risk Factor for Self Injury Behavior among 222 yowng of 
children with Autistic. Gournal of Intllectual Disability Research, Vol 47, No 8, PP 622-627.

Soares, D., Vannest, K., \& Harrison, J.(2009). Computer Aided self- Monitoring to increase Academic Production and Reduse self-Injury Behavior in A child with Autism. Journal Autism Behavioral Intervioral interventions, Vol 28, NO 24, PP 171-183. 